\title{
Intraoperative Local Ablative Therapies Combined with Surgery for the Treatment of Bilobar Colorectal Liver Metastases
}

\author{
MATTEO BARABINO ${ }^{1}$, ANDREA GATTI ${ }^{1}$, ROBERTO SANTAMBROGIO ${ }^{1}$, \\ MICOL POLIZZI $^{1}$, CARMELO LUIGIANO $^{2}$ and ENRICO OPOCHER ${ }^{1}$ \\ Units of ${ }^{1}$ HPB surgery and ${ }^{2}$ Endoscopy, Santi Paolo e Carlo Hospital, University of Milan, Milan, Italy
}

\begin{abstract}
Aim: To investigate the role of intraoperative local ablation techniques (LATs) in bilobar colorectal liver metastases (bCRLM). Patients and Methods: Among patients who underwent LAT for CRLM between 2005 and 2015, we selected 33 patients with bilobar disease submitted to thermal ablation alone or associated to liver resection. Primary end-point was complete local response at one month (CLR). Secondary end-points were morbidity, mortality, disease-free survival (DFS), local tumor recurrence (LTR) and long-term survival. Results: CLR was observed in 100\% of cases, while LTR occurred in 8 cases (22\%). DFS at 1, 3 and 5 years was 37\%, 5\% and 5\%. Overall survival (OS), in the same interval, was $95 \%, 49 \%$ and $26 \%$. Univariate analysis found a significant correlation between LTR and tumor size $(11 \% \leq 20 \mathrm{~mm}$ vs. $50 \%>20 \mathrm{~mm}$; $p=0.009)$. Conclusion: LAT is an effective adjuvant strategy in bCRLM for nodules within $20 \mathrm{~mm}$ diameter.
\end{abstract}

Liver resection is the only curative option in patients with bilobar liver metastases from primary colorectal cancer (bCRLMs), providing 5-year survival rates up to 58\%, according to low mortality $(1-3 \%)(1,2)$. Unfortunately, only $15-20 \%$ of patients with bCRLMs are suitable for upfront liver resection. In the last decade, the mutual integration among surgical techniques, multi-specialty treatments (portal embolization, local ablation techniques, two-stage hepatectomy) and new anti-angiogenic agents significantly improved resectability rate up to $16-30 \%$ (3).

The introduction of LATs in combination with resection,

Correspondence to: Andrea Gatti, MD, Ospedale San Paolo, HPB surgery Unit, Via Di Rudinì 8, 20142, Milan, Italy. Tel: +39 0250323069, Fax: +39 0250323075, e-mail: andreavaler. gatti@gmail.com

Key Words: Bilobar liver metastases, radiofrequency, microwave, local ablative therapy, hepatic resection, local tumor recurrence. scheduled in a single intervention or in a two-stage procedure for bCRLM, initially proposed with enthusiasm by French authors (4-6), was later widely criticized (7) and, thus, judged unsuitable for a randomized clinical trial (8). Considering the lack of evidence in the literature, the exact role of LAT in this field remains unclear. The primary endpoint of this observational study was complete local response (CLR) after LATs at one month. Secondary end-points were morbidity, mortality, local tumor recurrence (LTR), diseasefree survival (DFS) and long-term survival.

\section{Patients and Methods}

Study design and patient eligibility. We planned this observational study following the checklist of items included in the STROBE Statement (9). A prospective database of treated patients affected by bCRLM from a single Institution (San Paolo Hospital, Milan, Italy), between November 2005 and August 2015, was retrospectively analyzed. A multidisciplinary team, including surgeons, radiologists and oncologists, determined the eligibility for invasive treatment. When feasible, hepatectomy was considered the treatment of choice, aiming to R0 resection, vascular inflow and outflow maintenance, as well as adequate functional residual liver volume (10). All patients had pathologically confirmed colorectal adenocarcinoma. Most cases (29/38) underwent previous resection of the primary tumor. Patients were considered eligible if affected by synchronous or metachronous bCRLM (diagnosed six months after primary tumor), whether initial or recurrent, treated or not with chemotherapy, in absence of extrahepatic disease.

Patients with unresectable bCRLM $<50 \mathrm{~mm}$, unsuitable for hepatectomy, were considered for LAT procedure, either alone in the event of patients unfit for surgery (advanced age, comorbidities and/or personal refusal) or in combination with liver resection, in the presence of inadequate functional residual liver volume or residual tumor in the liver remnant.

Patients who developed disease progression after perioperative chemotherapy and/or were affected by extrahepatic localization were excluded from the study.

Technical notes. For our initial experience, we used a 18-Gauge radiofrequency cool tip type needle delivering, via a dedicated generator, $200 \mathrm{~W}$ waves and $480 \mathrm{KHz}$ (Valleylab, Boulder, CO, 
USA) for a standard time of 12 minutes, obtaining areas of necrosis not exceeding $26 \mathrm{~mm}$. To cope with larger lesions, in this first phase, a radio frequency system with 3 parallel needles, defined Cluster, was adopted.

Since February 2009, a 2.45-MHz microwave generator (AMICA-GEN, HS Hospital Service SpA, Aprilia, Lazio, Italy) providing energy through a 14- or 16-Gauge internally cooled coaxial antenna has also been adopted. This features a miniaturized quarter-wave impedance transformer (referred to as a minichoke) for reflected wave confinement. The minichoke antenna design, protected by an industrial patent (PCT/IB2002/00299), owned by the Italian National Council for Research, provided a quasi-spherical radiation pattern without increasing the probe diameter (14-Gauge at most). According to the tumor size, a single microwave energy application was delivered into the tissue, ranging from 45 to $70 \mathrm{~W}$ net power at the applicator end, for a total period of 5-10 min. Microwave ablation (MWA) could generate greater areas of necrosis, more homogeneous and in lesser ablative time, allowing us to treat lesions greater than $3 \mathrm{~cm}$. For any type of ablation system pursued, intraoperative ultrasound guidance was considered mandatory to define the needle route.

Hepatectomies were classified according to the Brisbane 2000 terminology (12). An experienced hepatobiliary surgeon carried out all surgical procedures. Open liver surgery was performed by subcostal or J-shape incision; as a standard procedure, vascular and biliary anatomy were evaluated via intraoperative ultrasound (IOUS). Pringle's maneuver was performed in selected cases; irrigated bipolar forceps and ultrasound knife were adopted for parenchymal transections in most cases. Other transection techniques included the use of cavitron ultrasonic surgical aspirator (USU; Olympus, Tokyo Japan).

Pre- and postoperative workup. Preoperative workup systematically involved thoraco-abdomino-pelvic computed tomography (CT), abdominal and liver ultrasonography (contrast-enhanced in some cases), eventually magnetic resonance imaging (MRI), carcinoembryonic antigen (CEA) level and indocyanine green clearance. A volumetric analysis of the future functional liver remnant was performed to assess the possibility for resection in one or two stages. Liver ultrasound and dynamic CT scan were performed within 1 month after surgical treatment to check complete local response (CLR). Spiral CT scan were performed after 3 and 6 months to assess the local response. Once the treated area was detected on helical CT scan, further contiguous 5-mm thick axial incremental scans were obtained in order to evaluate the resulting necrosis. LAT was defined successful if the aforementioned hypoattenuating area did not show contrast enhancement (13). An experienced radiologist reviewed all CT scans.

Publication bias. The postoperative results after LAT have been $a$ priori negatively conditioned by advanced liver disease burden, not amenable to upfront surgery because of inadequate functional reserve in the liver remnant, major vascular involvement (10) or poor performance status. Moreover, the small sample of cases included in the study (38 cases in 33 patients), could represent a setback to statistical analysis' relevance. Focusing on this point, Weng et al. (14) showed, in a recent meta-analysis, a mean number of 37 patients submitted to LATs enrolled for each study in which location of the nodules (unilobar/bilobar) was not specified. Thus, considering 38 cases with CRLM submitted to LATs, the series reported in the present study could be deemed significant. According to the study design, the sub-group of patients affected by bilobar disease has been selected in order to better understand the real impact of the procedure in this advanced setting.

Statistical analysis. Data were collected retrospectively from an electronic database (FileMaker Pro 8.5 Advanced ${ }^{\circledR}$, Filemaker Inc., Santa Clara, CA, USA) and exported to Microsoft Excel ${ }^{\circledR} 2010$ release for Microsoft Windows XP. For statistical analysis, the Stata ${ }^{\circledR} 10$ program (Stata Corporation, College Station, TX, USA) was used. The survival curves were obtained by Kaplan-Meier method; the correlation between the main parameters and the occurrence of relapse was investigated through the most common statistical index $\left(\chi^{2}\right.$, Fisher's exact test, Pearson's correlation coefficient). The $5 \%$ confidence interval (CI) was considered as statistically significant $(p<0.05)$.

\section{Results}

Between 2005 and 2015, sixty-one consecutive patients affected by colorectal liver metastases underwent LAT (either radiofrequency ablation (RFA or MWA) whether or not combined with hepatic resection. Among them, we selected 33 patients (38 interventions) with bCRLM (Figure 1). Baseline patients' characteristics are summarized in Table I.

Most patients were male with synchronous disease $(68.5 \%)$ and a previous history of chemotherapy $(65.7 \%)$. LATs were used in association with liver surgery in $84.2 \%$ $(n=32)$ of cases (LAT-R), predominantly in a single intervention (79\%). In eight cases, a stepwise surgical strategy was adopted via a two-stage hepatectomy (TSH). In most cases, LAT was associated with minor $(22 / 32,68.7 \%)$ hepatic resection, mainly via laparotomic approach $(34 / 38$, $89.5 \%)$. Concomitant resection of the primary tumor occurred in 9 cases $(23.6 \%)$.

Six cases underwent LAT without liver surgery. Four of them underwent concomitant laparoscopic resection of primary tumor within a staged procedure, while two patients with tiny and deep liver nodules (2 and 3 lesions, respectively) were submitted to LAT because of unfitness for both surgery and systemic therapy due to elderly age and comorbidity.

Referring to LATs (Table II), the most widely used technique was RFA $(30 / 38,79 \%)$ via a single $(26 / 38,68.4 \%)$ or Cluster needle $(4 / 38,10.5 \%)$; MWA, introduced since 2009 , was adopted in 8 procedures $(21 \%)$.

Eventually, a total of 89 lesions with an average diameter of $20 \mathrm{~mm}$ (standard deviation, $\mathrm{SD}= \pm 9$; median $=18$, range $=8$ 50) were treated with RFA/MWA. In 27 cases, ablation was performed on more than a single nodule (median=2, range $=1-5)$. Compared to RFA, metastases treated with MWA were fewer (26 vs. 63) but larger in diameter (mean=23 vs. $19 \mathrm{~mm}$; median=20 vs. $16 \mathrm{~mm}$ ) (Table II).

Operative time $($ mean $=86$ vs. $296 \mathrm{~min}$; median=65 vs. 280 min) and blood loss (mean=0 vs. $476 \mathrm{ml}$; median=0 vs. $375 \mathrm{ml}$ ) 


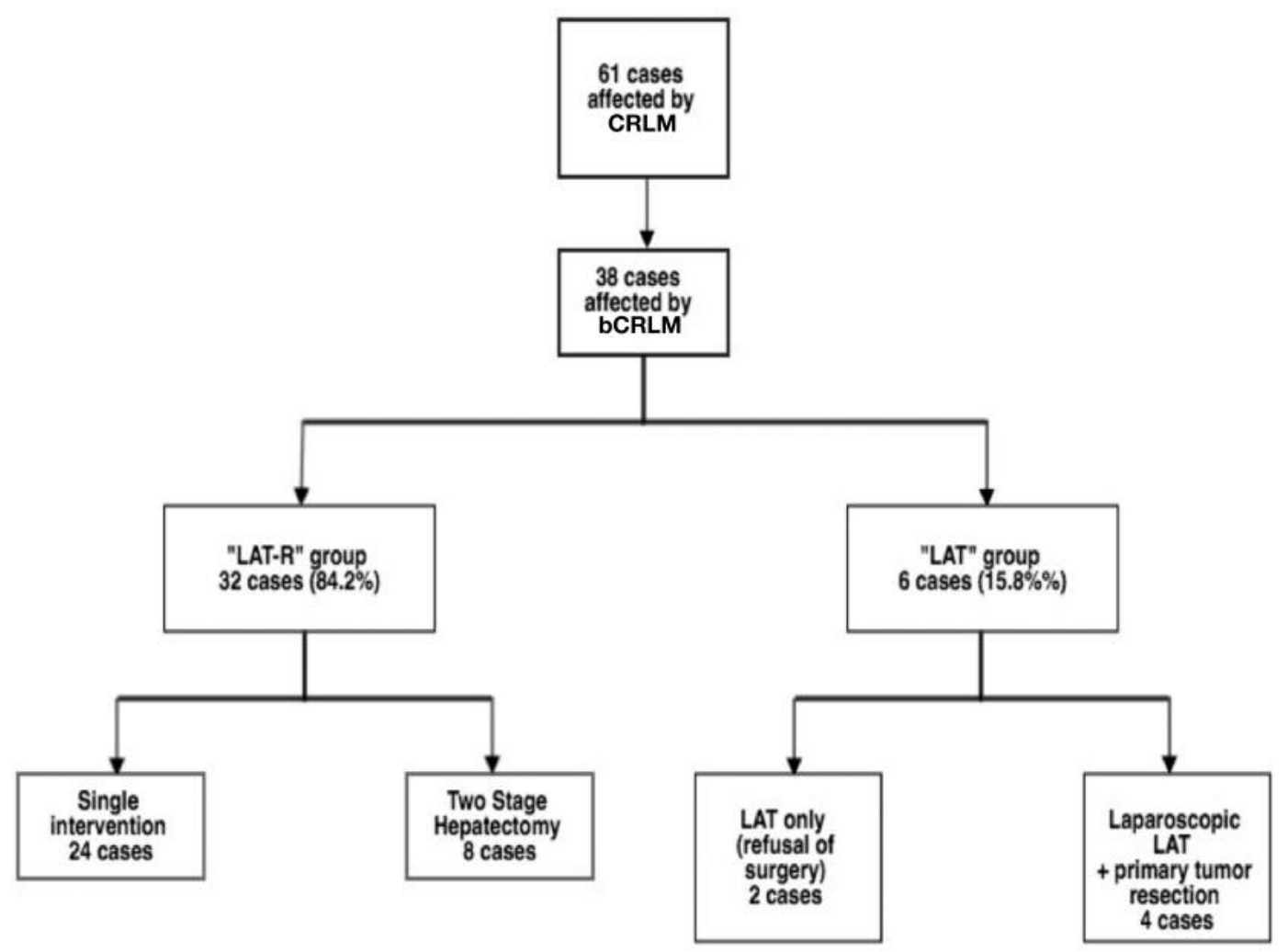

Figure 1. Patients' selection. CRLM, colorectal liver metastases; bCRLM, bilobar colorectal liver metastases; LAT, local ablative therapy; LAT-R, local ablative therapy and hepatic resection.

were expected to be greater for the combined intervention (Table III). The median postoperative hospital stay was 9 days (range $=4-29$ ). No mortality was observed.

The postoperative complication rate was $21 \%$, involving mainly the respiratory system $(4 / 8,50 \%)$. Complications directly attributable to the ablation procedure (pleural effusion) occurred in a single case. According to the DindoClavien classification of surgical complications, we found, respectively, in $37.5 \%$ a major grade I, in $25 \%$ a grade II, in $37.5 \%$ a grade III. No case presenting a grade IV was registered. Complication grade III consisted of a biliary leakage and an infected collection at the cut surface. These complications requested the placement of a biliary drainage through endoscopic retrograde cholangiopancreatography (ERCP) and an abdominal drainage under CT guidance, respectively. In the LAT group, a single case of acute respiratory failure occurred, due to chronic obstructive pulmonary disease exacerbation, not requiring intensive care unit (ICU).

Median follow-up in the study was 30 months (range $=3$ 156). CLR of LATs at one month was observed in $100 \%$ of cases. DFS rate at 1,3 and 5 years was $37 \%, 5 \%$ and $5 \%$, respectively (Table IV, Figure 2a). One-, three- and 5-year overall survival (OS) rates were $95 \%, 49 \%$ and $26 \%$ (Table
Table I. Preoperative characteristics of patients.

\begin{tabular}{lc}
\hline Patients' characteristics & Total No of cases (n=38) \\
\hline Age (mean, range) & $58 \pm 9.6(36-78)$ \\
Gender & $28(73.6 \%)$ \\
M & $10(26.3 \%)$ \\
F & \\
Primary tumor & $24(63.1 \%)$ \\
Colon & $14(36.9 \%)$ \\
Rectum & \\
Primary nodal status & $12(31.5 \%)$ \\
Negative & $26(68.5 \%)$ \\
Positive & \\
Timing of colorectal liver metastases & $26(68.5 \%)$ \\
Synchronous & $12(31.5 \%)$ \\
Metachronous & $13(34.3 \%)$ \\
Neoadjuvant chemotherapy & $25(65.7 \%)$ \\
N & \\
Y &
\end{tabular}

IV, Figure 2b). Concerning the LAT group, OS at 1, 3 and 5 years represented $85 \%, 50 \%$ and $33 \%$, while DFS, in the same interval, was assessed in $33 \%, 0 \%$ and $0 \%$ of cases (Table IV). 
Table II. Characteristics of local ablation techniques (LATs).

\begin{tabular}{|c|c|c|c|}
\hline Characteristics of LATs & $\begin{array}{l}\text { Total No of cases } \\
\qquad(\mathrm{n}=38)\end{array}$ & $\begin{array}{l}\text { Radiofrequency ablation (RFA) } \\
\qquad(\mathrm{n}=30)\end{array}$ & $\begin{array}{l}\text { Microwave Ablation (MWA) } \\
\qquad(\mathrm{n}=8)\end{array}$ \\
\hline Total no. of ablations & 89 & 63 & 26 \\
\hline For single lesion & $11(29 \%)$ & $11(37 \%)$ & $0(0 \%)$ \\
\hline For multiple lesions & $27(71 \%)$ & $19(63 \%)$ & $8(100 \%)$ \\
\hline \multicolumn{4}{|l|}{ Colorectal liver metastases diameter } \\
\hline Mean (standard deviation), $\mathrm{mm}$ & $20( \pm 9)$ & $19( \pm 9)$ & $23( \pm 9)$ \\
\hline Median (range), $\mathrm{mm}$ & $18(8-50)$ & $16(8-50)$ & $20(15-40)$ \\
\hline$<20 \mathrm{~mm}$ & $28(73 \%)$ & $23(77 \%)$ & $5(63 \%)$ \\
\hline$>20 \mathrm{~mm}$ & $10(27 \%)$ & $7(23 \%)$ & $3(37 \%)$ \\
\hline
\end{tabular}

Table III. Perioperative results.

\begin{tabular}{lccc}
\hline & $\begin{array}{c}\text { Total number of cases } \\
(\mathrm{n}=38)\end{array}$ & $\begin{array}{c}\text { Local ablation technique (LAT) } \\
(\mathrm{n}=6)\end{array}$ & $\begin{array}{c}\text { Local ablative therapy and hepatic resection (LAT-R) } \\
(\mathrm{n}=32)\end{array}$ \\
\hline $\begin{array}{l}\text { Operative time } \\
\text { Mean, min }\end{array}$ & $263( \pm 107)$ & $86( \pm 67)$ & $296( \pm 107)$ \\
$\quad$ Median (range) & $270(25-540)$ & $65(25-210)$ & $280(150-540)$ \\
Blood loss & & $0( \pm 0)$ & $476( \pm 413)$ \\
$\quad$ Mean, ml & $401( \pm 417)$ & 0 & $375(100-2300)$ \\
$\quad$ Median (range) & $300(0-2300)$ & $33 \%(2 / 6)$ & $19 \%(6 / 32)$ \\
Morbidity & $21 \%$ & $17 \%$ & 0 \\
$\quad$ Overall (\%) & $0 \%$ & 0 & $10( \pm 4.6)$ \\
Ablation-related(\%) & 0 & $10( \pm 4)$ & $9(6-29)$ \\
In-hospital mortality & & $10(4-16)$ & 0 \\
Length of stay & $10( \pm 4.5)$ & & \\
$\quad$ Mean, days & $9(4-29)$ & & \\
Median (range) & & &
\end{tabular}

Table IV. Univariate analysis.

\begin{tabular}{|c|c|c|c|c|}
\hline & \multicolumn{2}{|c|}{ Overall survival (OS) (\%) } & \multicolumn{2}{|c|}{ Disease-free survival (DFS) $(\%)$} \\
\hline & $1 / 3 / 5$ years & $p$-Value & $1 / 3 / 5$ years & $p$-Value \\
\hline Procedure & & 0.60 & & 0.57 \\
\hline Both groups & $95 / 49 / 26$ & & $37 / 5 / 5$ & \\
\hline Local ablation technique (LAT) & $83 / 50 / 33$ & & $33 / 0 / 0$ & \\
\hline Local ablative therapy and hepatic resection (LAT-R) & $91 / 45 / 24$ & & $34 / 6 / 6$ & \\
\hline No. of lesions & & 0.85 & & 0.35 \\
\hline Single lesion & $82 / 55 / 27$ & & $45 / 9 / 9$ & \\
\hline Multiple lesions & $92 / 46 / 25$ & & $33 / 4 / 4$ & \\
\hline Type of thermal ablation & & 0.26 & & 0.44 \\
\hline Microwave ablation (MWA) & $87 / 29 / 29$ & & $38 / 0 / 0$ & \\
\hline Radiofrequency ablation (RFA) & $93 / 53 / 27$ & & $37 / 7 / 7$ & \\
\hline Lesion diameter & & 0.21 & & 0.93 \\
\hline$\leq 20 \mathrm{~mm}$ & $93 / 56 / 28$ & & $36 / 7 / 7$ & \\
\hline$>20 \mathrm{~mm}$ & $90 / 30 / 20$ & & $40 / 0 / 0$ & \\
\hline
\end{tabular}


a

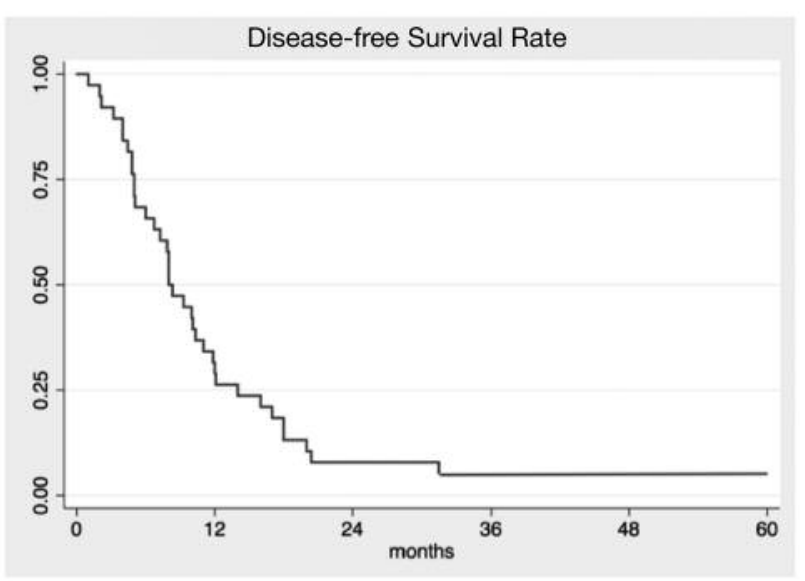

b

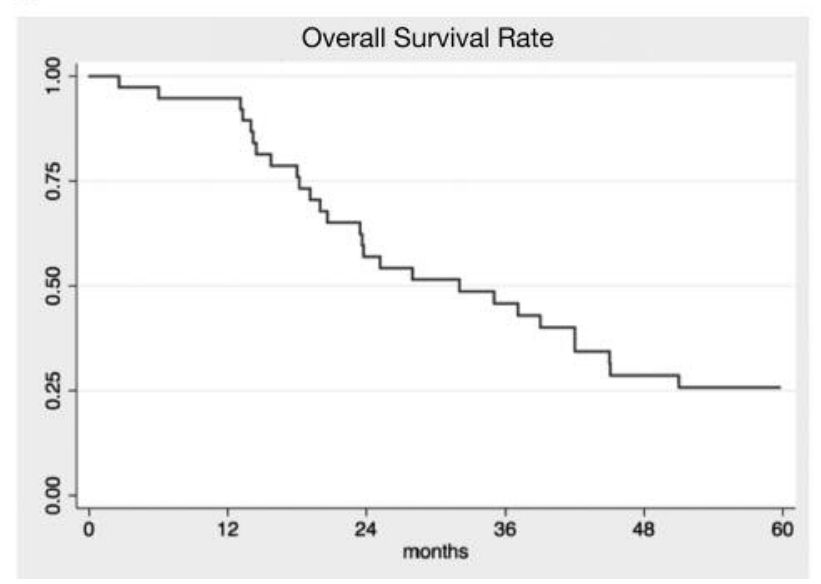

Figure 2. Disease-free survival (a) and overall survival rate (b) of 38 cases.

OS at 1,3 and 5 years for LAT-R was $91 \%, 45 \%$ and $24 \%$, while DFS, in the same interval, was assessed in $34 \%$, $6 \%$ and $6 \%$ of cases.

Specifically, over the study period, overall recurrences were observed in 36 cases $(94.5 \%, 29$ confined to the liver and 7 extended to extrahepatic sites). Liver relapses were focused in the area of ablation in $22 \%$ of cases, $50 \%$ of cases in the same segment, $30 \%$ in another segment.

Out of 36 patients affected by hepatic recurrence, 13 cases underwent a novel invasive treatment (36.1\% of patients). Repeated invasive treatment were LAT in 3 cases, LAT and hepatic resection in 5 cases, extrahepatic resection in a single case. In this small setting, only 4 patients relapsed again, still benefiting -in 3 cases- of an invasive treatment ( 1 thermal ablation, 1 thermal ablation and liver resection, a single lung thermal ablation followed by lobectomy a year later). In a single case, hepatic recurrence was treated with chemotherapy alone $(2.7 \%)$.

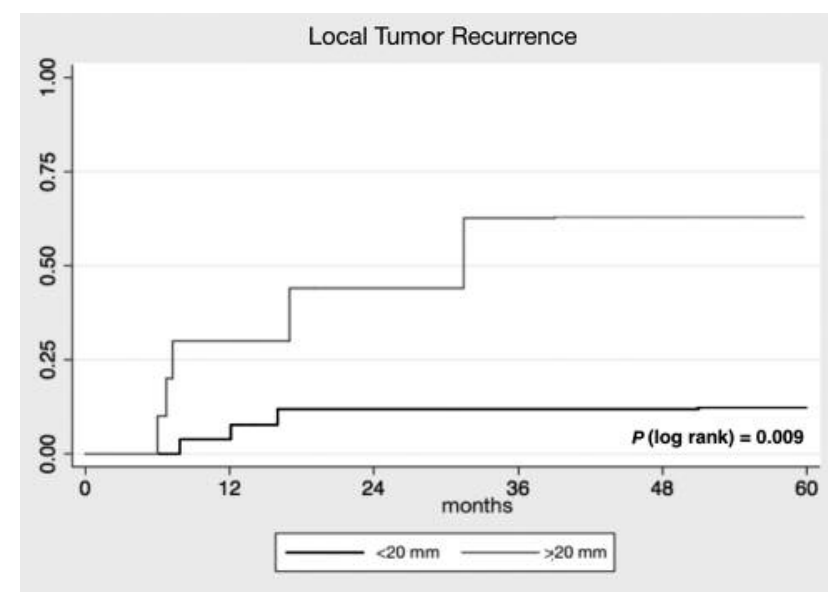

Figure 3. Correlation between local tumor recurrence (LTR) and tumor diameter.

Among the different variables considered at univariate analysis (single vs. multiple lesions, MWA vs. RFA, tumor diameter; Table V) a statistically significant correlation was found within LTR and tumor size $(11 \%$ for lesions $\leq 20 \mathrm{~mm}$ vs. $50 \%$ for lesions $>20 \mathrm{~mm}, p=0.009$; Figure 3). Furthermore, DFS did not show a statistically significant correlation within the number of treated lesions, nor did tumor dimension.

\section{Discussion}

Our study demonstrated that LATs combined with surgery is a potentially curative treatment to selected patients with otherwise unresectable bilobar liver disease, by showing a $100 \%$ CLR at one month. Furthermore, LAT proved to be a safe procedure with low morbidity $(21 \%)$, an acceptable LTR (22\%) and 5-year survival (26\%), thus confirming that multidisciplinary and multimodal approaches could even enhance treatment perspective in advanced bCRLM.

The morbidity and mortality of LATs, adopted to cope with unresectable disease with a curative intent, were favorable in our study; $21 \%$ and $0 \%$, respectively. Since LAT for bCRLM is almost exclusively associated to liver resection, the evalution of a peculiar morbidity due to LATs remains difficult to define. Previous studies (18, 24, 26-27) reported postoperative overall and liver-related complications, not defining LATs specific morbidity in this setting. Elias et al. described a $27 \%$ morbidity rate after LAT-R (25), referring to LAT a possible contribution to some transient liver insufficiency or right pleural effusion. In our series, postoperative complication rate was $21 \%$, where, in a single case, pleural effusion was directly related to LAT. 
Table V. Univariate analysis.

\begin{tabular}{|c|c|c|c|c|}
\hline & \multicolumn{2}{|c|}{ Recurrence $(\mathrm{n}=36,95 \%)$} & \multicolumn{2}{|c|}{ Local tumor recurrence $(\mathrm{LTR})(\mathrm{n}=8,22 \%)$} \\
\hline & No. of cases $(\%)$ & $p$-Value & No. of cases $(\%)$ & $p$-Value \\
\hline Procedure & & 0.53 & & 0.42 \\
\hline Local ablation technique (LAT) & $6(100 \%)$ & & $2(33 \%)$ & \\
\hline Local ablative therapy and hepatic resection (LAT-R) & $30(93 \%)$ & & $6(19 \%)$ & \\
\hline No. of lesions & & 0.50 & & 0.25 \\
\hline Single lesion & $10(90 \%)$ & & $1(9 \%)$ & \\
\hline Multiple lesions & $26(96 \%)$ & & $7(26 \%)$ & \\
\hline Type of thermal ablation & & 0.45 & & 0.20 \\
\hline Microwave ablation (MWA) & $8(100 \%)$ & & $3(37 \%)$ & \\
\hline Radiofrequency ablation (RFA) & $28(93 \%)$ & & $5(17 \%)$ & \\
\hline Lesion diameter & & 0.39 & & 0.009 \\
\hline$\leq 20 \mathrm{~mm}$ & $26(93 \%)$ & & $3(11 \%)$ & \\
\hline$>20 \mathrm{~mm}$ & $10(100 \%)$ & & $5(50 \%)$ & \\
\hline
\end{tabular}

The drawback in our series of this effective and safe procedure has been the low 1-year DFS (37\%). This is an open issue closely related to the rate of local recurrence next to thermal ablation site (LTR), widely varying between $2 \%$ and $60 \%$, and directly related to the size of the target (29). LTR can be as high as $21.7 \%$ for metastases larger than $3 \mathrm{~cm}$ $(21,30)$ but it is considerably lower for smaller lesions varying between 1.6 and $3.8 \%(21-23)$. LTR rate was $9 \%$ in the CLOCC trial (16) and 4\% (2 of 49 patients) in the series reported by Evrard et al. (18), where the median size of the ablated lesions was $10 \mathrm{~mm}$. Statistical analysis in our series significantly confirmed this trend, reporting LTR rates of $11 \%$ for nodules smaller than $20 \mathrm{~mm}$ versus $50 \%$ for larger metastases $(p=0.009)$. Nevertheless, if LAT-treated patients had a low DFS due to LTR, 36\% of them have been submitted to repeated curative treatments, thus finally obtaining an acceptable 5-years OS (26\%).

Prospective data on long-term survival after LAT for colorectal liver metastases are limited (16-18). The first phase 2 randomized trial on the efficacy of LAT for unresectable CRLM was proposed by Ruers et al. in 2012 (16); eligible patients $(n=119)$ were randomly assigned at a 1:1 ratio to receive LAT (eventually combined with surgery) plus systemic chemotherapy or systemic treatment alone. Location of the nodules (if unilobar or bilobar) was not specified. LAT (combined with liver surgery in $47 \%$ of cases) plus chemotherapy resulted in good survival (median OS rate of 45.3 months $v s .40 .5 p=0.22$ ) and in significant improvement of progression-free survival (PFS) at 3 years ( $27.6 \%$ vs. $10.6 \%$ of chemotherapy alone, $p=0.025$ ). This trial was criticized because the notable OS reported was also achieved in the control arm; thus, the real benefit of LAT in OS has still to be proved.
The second prospective study was published in the same year by Evrard et al. (18) and it was a multicenter, single arm, non-randomized phase 2 trial that evaluated the effectiveness of LAT with or without resection for the treatment of unresectable metastases (52 cases), $84 \%$ of which with bilobar presentation. After a median follow-up time of 34.8 months, the authors observed a 5-year OS rate of $43 \%$ and a 3 -year event-free survival rate of $10 \%$. Other retrospective series reported 5-year OS rates ranging from $17.9 \%$ to $49 \%$ (16); among them, French authors in particular remarked the role of LAT in bCRLM multimodal treatment. Elias et al. first reported the proficiency of LAT combined with surgery for bCRLM, in a one-step procedure, thus describing the so called "post-RF-trans-metastasis-hepatectomy (PRTMH)", to treat bilobar disease for small lesions located at the cut surface of a planned resection. This approach, applied on twenty-one patients, showed a notable 3-year OS (18\%) with no LTR after a median follow-up of 19.4 months (17). In spite of these promising results, the PRTMH approach for the treatment of bCRLM did not meet with wide appeal and, consequently, did not allow drawing conclusions regarding the real therapeutic impact of this procedure.

Nevertheless, the role of LATs within a one- or two-stage treatment of bCRLM is strengthened, as reported first by Adam et al. $(4,19)$ and recently by Faitot et al. $(20)$. In a casematch analysis (156 patients), Faitot et al. showed that median OS did not differ significantly between patients treated via one- or two-stage hepatectomy (37.2 and 34.5 months, $p=0.6$ ). The Authors confirmed that an aggressive strategy combining chemotherapy, surgery and LATs led to an appreciable OS of $36 \%$ in these advanced patients, stressing the major pitfall of the two-stage procedure as a drop-out rate up to $30 \%$ due to disease progression (20). In our series, $84 \%$ of cases 
underwent a combined procedure in one (79\%) or two steps. We did not observe any drop-out in the subset of eight patients submitted to TSH. OS at 1, 3 and 5 years for the LAT-R was $91 \%, 45 \%$ and $24 \%$, respectively, while DFS, in the same interval, was assessed in $34 \%, 6 \%$ and $6 \%$ of cases.

Our study has some specific bias (retrospective design, small sample of cases, advanced bilobar disease conditioning long-term results). Still, our series seems to stress that a multidisciplinary approach can make the difference in patients deemed to be untreatable. Nonetheless, proper selection of patients with bCRLM amenable to LAT-R is crucial in order to obtain low LTR.

In conclusion, the gold standard of care for bCRLM is liver resection. Thermal ablation plays a notable role, complementary to surgery, in patients affected by bCRLM since it allows higher resection rates in selected cases, otherwise not amenable to surgery. In our series, local ablative therapies associated with surgery show a low local tumor recurrence rate when adopted for lesions lesser than $20 \mathrm{~mm}$ in diameter.

\section{Conflicts of Interest}

The Authors declare that they have no competing interest.

\section{References}

1 Capussotti L: Surgical treatment of colorectal liver metastases. Springer-Verlag, Italy, 2011.

2 Abdalla EK, Vauthey JN, Ellis LM, Ellis V, Pollock R, Broglio $\mathrm{KR}$, Hess K and Curley SA: Recurrence and outcomes following hepatic resection, radiofrequency ablation, and combined resection/ablation for colorectal liver metastases. Ann Surg 239(6): 818-825, 2004.

3 Cirocchi R, Trastulli S, Boselli C, Montedori A, Cavaliere D, Parisi A, Noya G and Abraha I: Radiofrequency ablation in the treatment of liver metastases from colorectal cancer. Cochrane Database Syst Rev (6): CD006317, 2012.

4 Adam R, Laurent A, Azoulay D, Castaing D and Bismuth H: Two-stage hepatectomy: A planned strategy to treat irresectable liver tumors. Ann Surg 232(6): 777-785, 2000.

5 Elias D, De Baere TH, Mutillo I, Cavalcanti A, Coyle C and Roche A: Intraoperative use of radiofrequency treatment allows an increase in the rate of curative liver resection. J Surg Oncol 67(3): 190-191, 1998.

6 Imai K, Allard MA, Castro Benitez C, Vibert E, Sa Cunha A, Cherqui D, Castaing D, Baba $\mathrm{H}$ and Adam R: Long-term outcomes of radiofrequency ablation combined with hepatectomy compared with hepatectomy alone for colorectal liver metastases. Br J Surg 104(5): 570-579, 2017.

7 Wood CB, Gillis CR and Blumgart LH: A retrospective study of the natural history of patients with liver metastases from colorectal cancer. Clin Oncol 2(3): 285-288, 1976.

8 Kopetz S, Chang GJ, Overman MJ, Eng C, Sargent DJ, Larson DW, Grothey A, Vauthey JN, Nagorney DM and McWilliams RR: Improved survival in metastatic colorectal cancer is associated with adoption of hepatic resection and improved chemotherapy. J Clin Oncol 27(22): 3677-3683, 2009.
9 von Elm E, Altman DG, Egger M, Pocock SJ, Gøtzsche PC and Vandenbroucke JP, STROBE Initiative: The Strengthening the Reporting of Observational Studies in Epidemiology (STROBE) statement: Guidelines for reporting observational studies. Lancet 370(9596): 1453-1457, 2007.

10 Adams RB, Aloia TA, Loyer E, Pawlik TM, Taouli B and Vauthey JN, Americas Hepato-Pancreato-Biliary Association, Society of Surgical Oncology, Society for Surgery of the Alimentary Tract: Selection for hepatic resection of colorectal liver metastases: Expert consensus statement. HPB (Oxford) 15(2): 91-103, 2013.

11 Gillams A, Goldberg N, Ahmed M, Bale R, Breen D, Callstrom M, Chen MH, Choi BI, de Baere T, Dupuy D, Gangi A, Gervais $\mathrm{D}$, Helmberger T, Jung EM, Lee F, Lencioni R, Liang $\mathrm{P}$, Livraghi T, Lu D, Meloni F, Pereira P, Piscaglia F, Rhim H, Salem R, Sofocleous C, Solomon SB, Soulen M, Tanaka M, Vogl T, Wood B and Solbiati L: Thermal ablation of colorectal liver metastases: A position paper by an international panel of ablation experts, the interventional oncology sans frontières meeting 2013. Eur Radiol 25(12): 3438-3454, 2015.

12 Belghiti $\mathrm{J}$ and Clavien PA, Terminology Committee of the IHPBA: Terminology of liver anatomy and resections. HPB (Oxford) 2: 333-339, 2000.

13 Lencioni R, Cioni D and Bartolozzi C: Percutaneous radiofrequency thermal ablation of liver malignancies: Techniques, indications, imaging findings, and clinical results. Abdom Imaging 26(4): 345-360, 2001.

14 Weng M, Zhang Y, Zhou D, Yang Y, Tang Z, Zhao M, Quan Z and Gong W: Radiofrequency ablation versus resection for colorectal cancer liver metastases: A meta-analysis. PLoS One 7(9): e45493, 2012.

15 Viganò L, Capussotti L, Lapointe R, Barroso E, Hubert C, Giuliante F, Ijzermans JN, Mirza DF, Elias D and Adam R: Early recurrence after liver resection for colorectal metastases: Risk factors, prognosis, and treatment. A Liver MetSurvey-based study of 6,025 patients. Ann Surg Oncol 21(4): 1276-1286, 2014.

16 Ruers T, Punt C, Van Coevorden F, Pierie JP, Borel-Rinkes I, Ledermann JA, Poston G, Bechstein W, Lentz MA, Mauer M, Van Cutsem E, Lutz MP and Nordlinger B, EORTC GastroIntestinal Tract Cancer Group, Arbeitsgruppe Lebermetastasen und tumoren in der Chirurgischen Arbeitsgemeinschaft Onkologie (ALM-CAO), National Cancer Research Institute Colorectal Clinical Study Group (NCRI CCSG): Radiofrequency ablation combined with systemic treatment versus systemic treatment alone in patients with non-resectable colorectal liver metastases: A randomized EORTC Intergroup phase II study (EORTC 40004). Ann Oncol 23(10): 2619-2626, 2012.

17 Elias D, Manganas D, Benizri E, Dufour F, Menegon P, El Harroudi $\mathrm{T}$ and de Baere T: The trans-metastasis hepatectomy (through metastases previously ablated with radiofrequency): Results of a 13case study of colorectal cancer. J Surg Oncol 93(1): 8-12, 2006.

18 Evrard S, Rivoire M, Arnaud J, Lermite E, Bellera C, Fonck M, Becouarn Y, Lalet C, Puildo M and Mathoulin-Pellissier S: Unresectable colorectal cancer liver metastases treated by intraoperative radiofrequency ablation with or without resection. Br J Surg 99(4): 558-565, 2012.

19 Adam R, Delvart V, Pascal G, Valeanu A, Castaing D, Azoulay D, Giacchetti S, Paule B, Kunstlinger F, Ghémard O, Levi F and Bismuth H: Rescue surgery for unresectable colorectal liver metastases downstaged by chemotherapy: A model to predict long-term survival. Ann Surg 240(4): 644-658, 2004. 
20 Faitot F, Faron M, Adam R, Cimino M, Cherqui D, Vibert E, Castaing D, Cunha AS and Goéré D: Two-stage hepatectomy versus 1-stage resection combined with radiofrequency for bilobar colorectal metastases. A case-matched analysis of surgical and oncological outcomes. Ann Surg 260(5): 822-828, 2014.

21 Mulier S, Ni Y, Jamart J, Ruers T, Marchal G and Michel L: Local recurrence after hepatic radiofrequency coagulation: Multivariate meta-analysis and review of contributing factors. Ann Surg 242(2): 158-171, 2005.

22 Abitabile P, Hartl U, Lange J and Maurer CA: Radiofrequency ablation permits an effective treatment for colorectal liver metastasis. Eur J Surg Oncol 33(1): 67-71, 2007.

23 Leblanc F, Fonck M, Brunet R, Becouarn Y, Mathoulin-Pélissier $\mathrm{S}$ and Evrard S: Comparison of hepatic recurrences after resection or intraoperative radiofrequency ablation indicated by size and topographical characteristics of the metastases. Eur J Surg Oncol 34(2): 185-190, 2008.

24 Agcaoglu O, Aliyiev S, Karabulut K, El-Gazzaz G, Aucejo F, Pelley R, Siperstein AE and Berber E: Complementary use of resection and radiofrequency ablation for the treatment of colorectal liver metastases: An analysis of 395 patients. World J Surg 37(6): 1333-1339, 2013.

25 Elias D, Baton O, Sideris L, Matsuhisa T, Pocard M and Lasser $P$ : Local recurrences after intraoperative radiofrequency ablation of liver metastases: A comparative study with anatomic and wedge resections. Ann Surg Oncol 11(5): 500-505, 2004.

26 Wada Y, Takami Y, Tateishi M, Ryu T, Mikagi K and Saitsu H: Efficacy of surgical treatment using microwave coagulo-necrotic therapy for unresectable multiple colorectal liver metastases. Onco Targets Ther 25(9): 937-943, 2016.
27 Saxena A, Chua TC, Chu FC, Ng KM, Herle P and Morris DL: Impact of treatment modality and number of lesions on recurrence and survival outcomes after treatment of colorectal cancer liver metastases. J Gastrointest Oncol 5(1): 46-56, 2014.

28 van Amerongen MJ, van der Stok EP, Fütterer JJ, Jenniskens SF, Moelker A, Grünhagen DJ, Verhoef C and de Wilt JH: Shortterm and long-term results of patients with colorectal liver metastases undergoing surgery with or without radiofrequency ablation. Eur J Surg Oncol 42(4): 523-530, 2016.

29 Mulier S, Ni Y, Jamart J, Ruers T, Marchal G and Michel L: Local recurrence after hepatic radiofrequency coagulation: Multivariate meta-analysis and review of contributing factors. Ann Surg 242(2): 158-171, 2005.

30 Tanis E, Nordlinger B, Mauer M, Sorbye H, van Coevorden F, Gruenberger T, Schlag PM, Punt CJA, Ledermann J and Ruers TJM: Local recurrence rates after radiofrequency ablation or resection of colorectal liver metastases. Analysis of the European Organisation for Research and Treatment of Cancer \#40004 and \#40983. Eur J Cancer 50(5): 912-919, 2014.

Received March 31, 2017

Revised April 11, 2017

Accepted April 12, 2017 